\title{
THE INTERNAL STRUCTURE OF POWDER-SNOW AVALANCHES
}

\author{
by
}

\author{
K. Nishimura, H. Narita, N. Maeno,
}

(The Institute of Low Temperature Science, Hokkaido University, Sapporo 060, Japan)

and

K. Kawada

(Toyama University, Toyama 930, Japan)

\section{ABSTRACT}

The internal structure of powder-snow avalanches was investigated at Kurobe Canyon in the Shiai-dani area of Japan in 1988. Internal velocity was derived for avalanches of this kind by frequency analysis of impact-force data, and was found to undergo a remarkable change with time. The shear of the avalanche flow was estimated to range from 1 to $7 \mathrm{~s}^{-1}$. The front region of the avalanche wind was observed to precede the front of the avalanche by a distance of $17.3 \mathrm{~m}$. The maximum wind velocity was comparable with the internal velocity of the front region of the avalanche.

\section{INTRODUCTION}

Field measurements of both impact pressures and front velocities of powder-snow avalanches have been carried out for several years, but information about their internal structure, including internal velocity, internal density, and avalanche wind, is quite scarce and mostly qualitative (Shimizu and others, 1980; McClung and Schaerer, 1985; Norem and others, 1985). In respect of the internal velocity, we can find only a solitary report by Salm and Gubler (1985), who measured avalanche-velocity distributions directly in artificially released dense-flow avalanches with $\mathrm{X}$-band microwave Doppler radar. Information about internal density has been given only by Schaerer (1975). Meanwhile, there are many reports of structures and trees being damaged or destroyed by the avalanche wind which precedes an avalanche front (Mellor, 1978; Hopfinger, 1983); it is of ten referred to as an air blast (Perla and Martinelli, 1976) or as air waves (Kotlyakov, 1977). However, it must be stressed that very little of the available information on avalanche winds has been derived from systematic observation.

In the Shiai-dani region, a systematic investigation of powder-snow avalanches is under way (Kawada and others, 1989). This paper gives the results of analysis of the data obtained in 1988, including some new findings on the internal structure of powder-snow avalanches.

\section{MEASUREMENTS}

Figure 1 shows the schematic diagram of our measuring apparatus set up in an avalanche chute. Most of the equipment was installed in two sets of steel mounds which consisted of cylinders $0.3 \mathrm{~m}$ in diameter and $5 \mathrm{~m}$ in height. Hereafter, we refer to the mounds as up-stream $A$ and down-stream $B$, respectively. The distance between $A$ and $B$ was $3.07 \mathrm{~m}$ along the avalanche chute and $2.50 \mathrm{~m}$ in the direction perpendicular to it.

Impact forces were measured with strain-gauge-type load cells, Kyowa LU2TE, attached to $10 \mathrm{~cm}$ diameter pressure plates. Three load cells were sited on each mound, at heights of $2.60,3.56$, and $4.33 \mathrm{~m}$ above the ground, in the arrangement shown in Figure 1. The horizontal distance between adjacent load cells, a and b, b and c, d and e, and $\mathrm{e}$ and $\mathrm{f}$ was always $0.5 \mathrm{~m}$.

The velocity of the wind induced by avalanche flow was measured with an ultra-sonic anemometer, Kaijodenki WA-200, with a high time resolution of $20 \mathrm{~Hz}$, which was able to sense not only the horizontal component of the wind but also the vertical one. The sensor was mounted on the top of mound $\mathrm{A}$, and all the data were recorded by two analogue data-recorders, Kyowa RTP650, located in a room in an underground tunnel.

\section{RESULTS}

Figure $2 a-f$ shows the recording of impact forces obtained during the passage of an avalanche which took place at $11.20 \mathrm{~h}$ on 3 February 1988. It broke out in such a heavy storm that the size and flow height of the avalanche could not be observed. The noise level of the impact-force records is about $3 \mathrm{kN} / \mathrm{m}^{2}$, and it will be seen that the avalanche persisted for about $6 \mathrm{~s}$ at the recording site. Kawada and others (1989) have classified these sets of data as belonging to a type I avalanche behaviour, which is characterized by a number of discrete sharp peaks. The wave forms observed at mound A appear to differ in nature from those obtained at mound $\mathrm{B}$; nonetheless, the three sets of data collected from the same mound do appear to resemble each other.

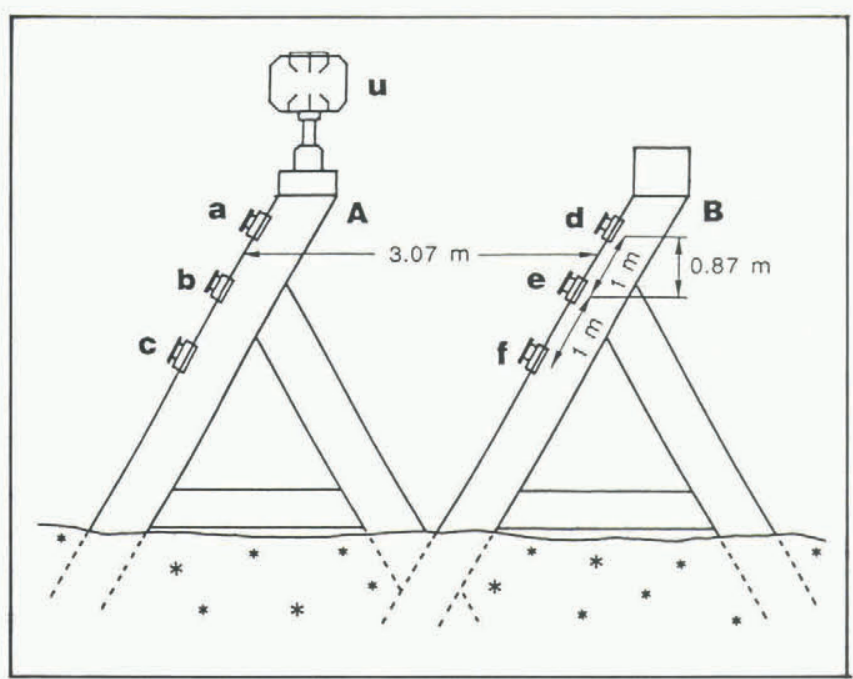

Fig. 1. Schematic representation of the measuring apparatus, set in an avalanche chute. a, b, and $c$ are the load cells sited on mound $\mathrm{A}$, and $\mathrm{d}, \mathrm{e}$, and $\mathrm{f}$ are those sited on mound B. $\mathrm{u}$ is an ultrasonic anemometer. 

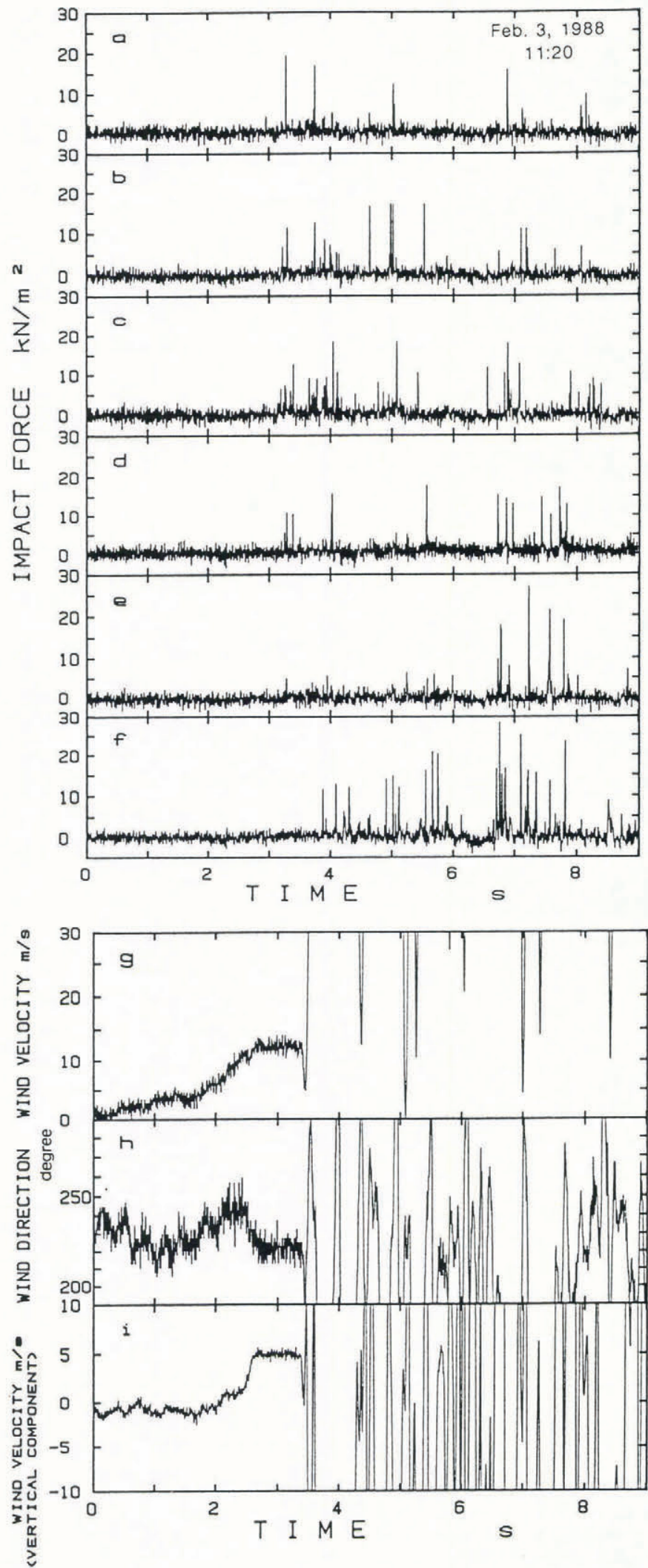

Fig. 2. Recordings of the impact forces and the wind strengths observed during the passage of an avalanche at $11.20 \mathrm{~h}$ on 3 February 1988. (a) $-(\mathrm{f})$ indicate the impact forces obtained using the load cells shown in Figure 1. (g)-(i) are recordings of the wind strengths obtained by use of the ultrasonic anemometer.

Figure $2 \mathrm{~g}-\mathrm{i}$ shows recordings of the wind caused by the avalanche; the wind velocity evidently began to increase about $1.5 \mathrm{~s}$ before the first peak of the impact force was observed, and reached a maximum of $12.3 \mathrm{~m} / \mathrm{s}$, which lasted for $0.8 \mathrm{~s}, 1 \mathrm{~s}$ after the arrival of the avalanche front. During the following $34 \mathrm{~s}$, abnormal velocity values were observed (Kawada and others, 1989), possibly due to the

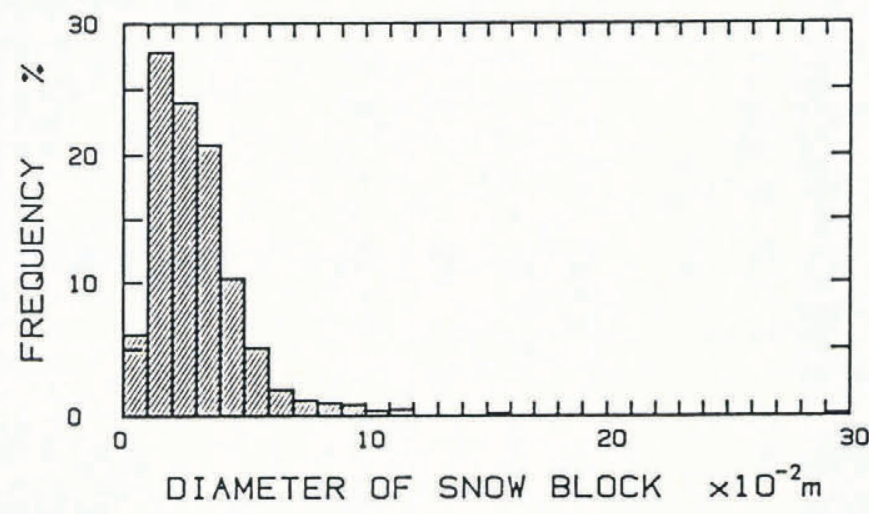

Fig. 3. Histograms of frequency of different dimensions of snow blocks in the snow-avalanche debris.

passage of the snow-dust region. The length of the snow-dust region was estimated from the recordings to be about $400 \mathrm{~m}$, based on an assumption that the snow dust moved with a mean velocity of $12 \mathrm{~m} / \mathrm{s}$.

The direction of the avalanche wind, $h$, was $225^{\circ}$, that is south-west, which corresponded exactly to the up-stream direction of the avalanche chute. The vertical component, $i$, of the wind velocity was almost zero before the avalanche broke out but it became $+5.0 \mathrm{~m} / \mathrm{s}$ during the passage of the avalanche wind. The + sign designates upward movement. Calculations using both the total and the vertical components of the wind velocity give a representation of the avalanche wind blowing upwards at an angle of $24^{\circ}$ from the horizon. It is expected that the origin of the upward component will be explained by the surrounding topographic conditions.

After the passage of the avalanche, many snow blocks remained in the snow-avalanche debris. Figure 3 gives histograms of the frequencies and diameters of some of these snow blocks. The corners of all the blocks were more or less rounded, and the diameters of the blocks were in the range $5-300 \mathrm{~mm}$. The bulk density of the blocks, measured $10 \mathrm{~h}$ later, was $220 \mathrm{~kg} / \mathrm{m}^{3}$, which is a value somewhat smaller than that of $250-300 \mathrm{~kg} / \mathrm{m}^{3}$ for the total snow debris.

\section{DISCUSSION}

The impact-force data recorded by means of analogue data recorders was transformed into digital values using an $A-D$ converter, Kyowa $\mathrm{ADC}-116 \mathrm{C}$, and noise was eliminated with a low-pass filter. The cross-correlation function was calculated at $1 \mathrm{~s}$ intervals of recording time from a series of impact-force data (Fig. $2 a-f$ ). The average internal velocity was obtained from a combination of the lag time that gave the highest correlation and the distance between the two measuring points. Further details of the method have been given in Nishimura and others (1987). Since the wave forms observed at mounds $\mathrm{A}$ and $\mathrm{B}$ were not similar to each other, calculations were carried out with the following pairings: (a) $-(b),(b)-(c),(d)-(e)$, and (e) $-(f)$.

Internal velocities along the avalanche chute are shown in Figure 4. Here, A shows the velocities obtained from the data for the mound $\mathrm{A}$, and $\mathrm{B}$ the velocities from data for mound B. Internal velocities showed rapid changes with time; $5-7 \mathrm{~m} / \mathrm{s}$ (A) and $15-18 \mathrm{~m} / \mathrm{s}$ (B), for the frontal region, and about $35 \mathrm{~m} / \mathrm{s}$ in the rear half of the core region. This is different from the pattern obtained by Salm and Gubler (1985), which showed maximum velocities to occur near the front region of an avalanche. In practice, not only air drag but also the compression and entrainment of snow at the front of the avalanche reduce its internal velocities. Thus, greater velocities can be reached in the latter half of the core than at the avalanche front, as shown in Figure 4. Although the distance between the two mounds $\mathrm{A}$ and $\mathrm{B}$ was only $3.1 \mathrm{~m}$ along the avalanche chute and $2.7 \mathrm{~m}$ perpendicular to it, the velocities registered at $\mathrm{A}$ and $B$ are rather different from each other. It can therefore be concluded that the internal structure of a powder-snow avalanche changes significantly. In general, the upper position velocities (a) $-(\mathrm{b}),(\mathrm{d})-(\mathrm{e})$ are $1-6 \mathrm{~m} / \mathrm{s}$ larger than 

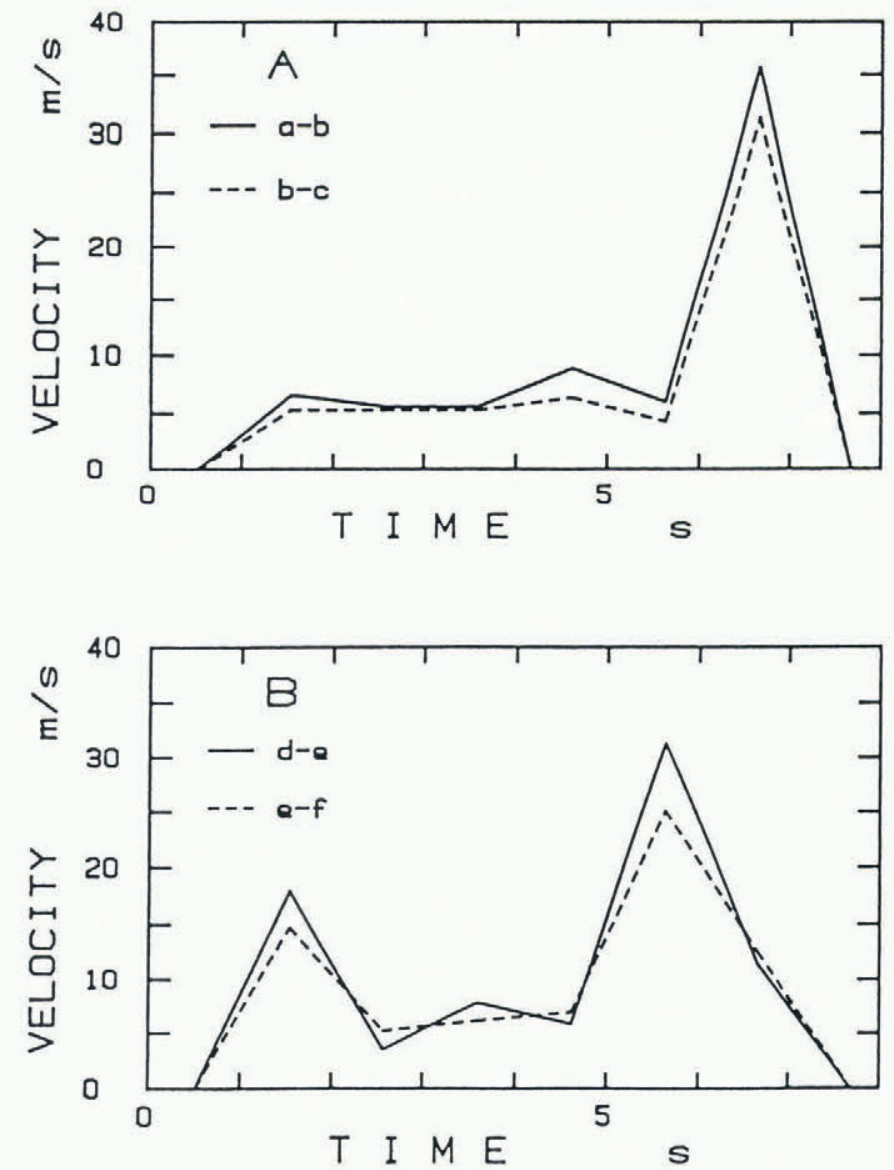

Fig. 4. Internal velocity of the avalanche that occurred on 3 February 1988. A was calculated from the recordings of impact forces from mound $A$, and $B$ from similar recordings from mound $B$.

the ones for the lower position (b) $-(\mathrm{c})$, (e)-(f). Taking account of the vertical distance of $0.87 \mathrm{~m}$ between adjacent load cells, the vertical velocity shear of the avalanche flow has been estimated to be in the range $1-7 \mathrm{~m} / \mathrm{s}$.

So far, little information has been gathered as to the structure of avalanche winds. Mellor (1968) estimated by simple calculation that potentially destructive wind forces are to be expected at $1.25 h_{\mathrm{e}}$ ahead of fast dust avalanches, where $h_{\mathrm{e}}$ is the effective height of the avalanche, for which air velocity is about 0.2 times greater than the front velocity, $U_{\mathrm{f}}$. Tochon-Danguy and Hopfinger (1975) showed in a salt-solution experiment that the flow induced by a head-of-gravity current has a velocity of $0.2 U_{\mathrm{f}}$ at a distance of $0.6 h$, where $h$ is the avalanche height.

If we assume for Figure $2 \mathrm{~g}-\mathrm{i}$ that the avalanche front arrived at the mounds when the anemometer began to give abnormal readings, then we may describe the following picture of the structure of the frontal region of this avalanche: the front of the avalanche wind preceded that of the avalanche body by $17.3 \mathrm{~m}$ (the figure was estimated as the product of the average wind velocity and the duration of avalanche movement); the wind velocity increased, reaching an almost constant value of $12.3 \mathrm{~m} / \mathrm{s}$ at a distance of $7.5 \mathrm{~m}$ behind the wind front; the wind velocity near the avalanche front was comparable with the averaged internal velocity for the frontal region $((a)-(b)=7 \mathrm{~m} / \mathrm{s}$, (d) $-(\mathrm{e})$ $=18 \mathrm{~m} / \mathrm{s}$ ). Figure 5 gives a schematic picture of the resulting structure.

\section{CONCLUSIONS}

The internal structure of a powder-snow avalanche was investigated by making observations at Kurobe Canyon, Japan, in 1988, and the following results were obtained:

Internal velocity, derived from the avalanche impact-force data, changed very rapidly with time.
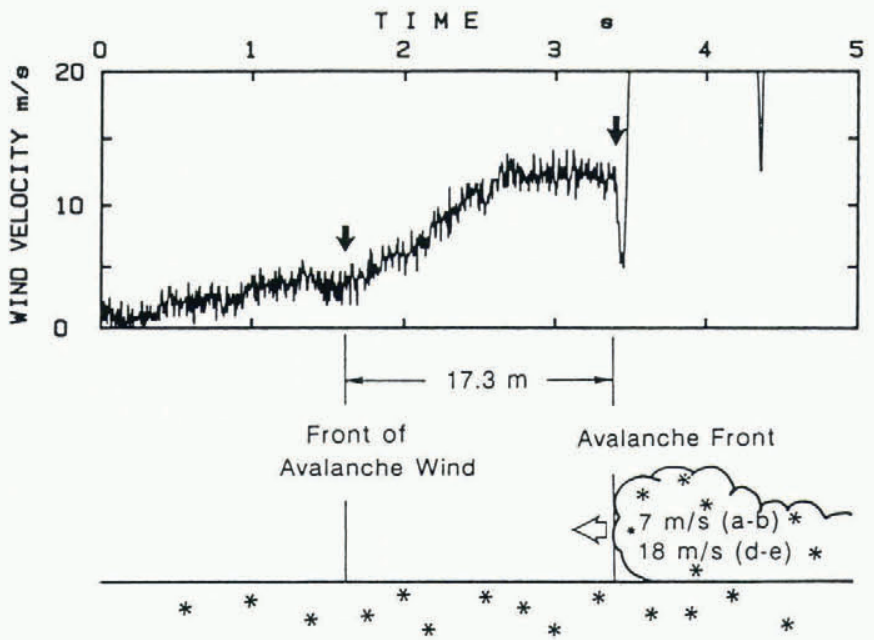

Fig. 5. Schematic picture showing the deduced structure of the avalanche wind.

The shear of the avalanche flow was estimated to be in the range $1-7 \mathrm{~s}^{-1}$.

The front of the avalanche wind was found to precede the front of the avalanche itself by a distance of about $17.3 \mathrm{~m}$.

The avalanche wind velocity, calculated as $12.3 \mathrm{~m} / \mathrm{s}$ from observations with an ultrasonic anemometer, was almost equal to the averaged internal velocity of the front region of the avalanche.

\section{ACKNOWLEDGEMENTS}

The authors would like to express their sincere thanks to the following individuals for their helpful co-operation: R. Naruse, G. Casassa, S. Kobayashi, K. Izumi, Y. Sato, H. Iida, and S. Kohno. They would also like to thank the Kansai Electric Power Company, who supported the project and made every effort with the logistic arrangements for the research operation; to the members of Japan Broadcasting Corporation, who recorded avalanches with video cameras and gave various other forms of assistance, and to many other colleagues and students who worked in the field. They are also indebted to local public officials, the North Japan Disaster Prevention Engineering Co., the Kokusai Kogyo Company, and the alpine guide, $\mathrm{Mr}$ I. Takashima, for their heartful assistance and guidance.

\section{REFERENCES}

Hopfinger, E.J. 1983. Snow avalanche motion and related phenomena. Annu. Rev. Fluid. Mech., 15, 47-76.

Kawada, K., K. Nishimura, and N. Maeno. 1989. Experimental studies on a powder-snow avalanche. Ann. Glaciol., 13, 129-134.

Kotlyakov, V.M., B.N. Rzhevskiy, and V.A. Samoylov. 1977. The dynamics of avalanching in the Khibins. $J$. Glaciol., 19(81), 431-439.

McClung, D.M. and P.A. Schaerer. 1985. Characteristics of flowing snow and avalanche impact pressures. Ann. Glaciol., 6, 9-14.

Mellor, M. 1968. Avalanches. CRREL Monogr., III-A 3 d.

Mellor, M. 1978. Dynamics of snow avalanches. In Voight, B., ed. Rockslides and avalanches. Vol. 1. Amsterdam, etc., Elsevier, 753-792.

Nishimura, K., N. Maeno, and K. Kawada. 1987. Internal structures of large-scale avalanches revealed by a frequency analysis of impact forces. Low Temp. Sci., Ser. $A, 46,91-98$. [In Japanese.]

Norem, H., T. Kvisterøy, and B.D. Evensen. 1985. Measurement of avalanche speeds and forces: instrumentation and preliminary results of the Ryggfonn project. Ann. Glaciol., 6, 19-22. 
Perla, R.I. and M. Martinelli. 1976. Avalanche handbook. U.S. Dep. Agric. Agric. Handb. 489.

Salm, B. and H. Gubler. 1985. Measurement and analysis of dense flow avalanches. Ann. Glaciol., 6, 26-34.

Schaerer, P.A. 1975. Friction coefficients and speed of flowing avalanches. International Association of Hydrological Sciences Publication 114 (Symposium at Grindelwald 1974 - Snow Mechanics), 425-432.
Shimizu, H., T. Huzioka, E. Akitaya, H. Narita, M. Nakagawa, and K. Kawada. 1980. A study on high-speed avalanches in the Kurobe canyon, Japan. J. Glaciol., 26(94), 141-151.

Tochon-Danguy, J.C. and E.J. Hopfinger. 1975. Simulation of the dynamics of powder avalanches. International Association of Hydrological Sciences Publication 114 (Symposium at Grindelwald 1974 - Snow Mechanics), 369-380. 